\title{
Universal Free Choice from Concessive Copular Conditionals in Tibetan
}

\author{
Michael Yoshitaka Erlewine ${ }^{(\otimes)}(\mathbb{D}$ \\ National University of Singapore, Singapore, Singapore \\ mitcho@mitcho.com
}

\begin{abstract}
I describe the expression of free choice in Tibetan, which involves the combination of a $w h$-word, copula, conditional morphology, and a scalar 'even' particle. I demonstrate that the conventional semantics of these ingredients successfully combine to derive universal free choice meaning. This motivates a new approach to the compositional semantics of universal free choice, which does not prescribe its universal force. This quantificational force is parasitic on the modal/temporal operator which is restricted by the conditional; the scalar 'even' particle then ensures that the conditional restricts a necessity modal.
\end{abstract}

Keywords: Free choice $\cdot$ wh $\cdot$ Copula $\cdot$ Conditionals $\cdot$ even $\cdot$ Tibetan

\section{Introduction}

This paper has two complementary goals. The first is to report on the expression of free choice in Tibetan, based on original fieldwork. ${ }^{1}$ Universal free choice items in Tibetan are a combination of a wh-word and the particle yin.na'ang, optionally preceded by a nominal domain. ${ }^{2}$

${ }^{1}$ The original data here reflect the grammars of three speakers of the Tibetan diaspora community in Dharamsala, India. One was born in Tibet and moved to India early in life; the other two were born in India. All grew up in the diaspora community with Tibetan as their first language. The data here was collected in Dharamsala in the summers of 2018 and 2019, and through some further correspondence.

2 Abbreviations: AUX $=$ auxiliary, $\mathrm{COND}=$ conditional, $\mathrm{COP}=$ copula, $\mathrm{IMPF}=$ imperfective, $\mathrm{NEG}=$ negation; $\mathrm{DAT}=$ dative, $\mathrm{ERG}=$ ergative, $\mathrm{GEN}=$ genitive. $\mathrm{I}$ employ Wylie romanization here, with periods indicating syllable boundaries where there is no morpheme boundary, as in Garrett 2001 (see note on p. 12).

I thank Kunga Choedon, Pema Yonden, and Tenzin Kunsang for patiently sharing their language with me. For earlier comments and discussion related to this project, I thank Maayan Abenina-Adar, Rahul Balusu, Kenyon Branan, Seth Cable, James Collins, Chris Davis, Kai von Fintel, Danny Fox, Hadas Kotek, Elin McCready, Ryan Walter Smith, two anonymous reviewers for the Workshop on Logic, Language, and Meaning, as well as audiences at NELS 50, the 2020 LSA, Triple A 7, Sinn und Bedeutung 25, and the National University of Singapore. I thank Zheng Shen and Wenkai Tay for comments on earlier drafts. This work is supported by a PYP start-up grant from the National University of Singapore.

(C) The Author(s) 2020

D. Deng et al. (Eds.): TLLM 2020, LNCS 12564, pp. 13-34, 2020.

https://doi.org/10.1007/978-3-662-62843-0_2 
Example (1) describes someone who is not picky about their food. Dumplings? Norbu eats them. Frog? He eats that too. Whatever the food, Norbu eats it.

The second goal is to motivate a new compositional semantics for universal free choice based on the overt morphosyntax of these Tibetan FCIs. Yin.na'ang is quite transparently the combination of the copular verb yin, ${ }^{3}$ conditional suffix na, and scalar focus particle yang 'even' (2). The combination may indeed appear transparently as yin.na.yang, but is commonly contracted to yin.na'ang in both writing and speech, and may further reduce to yin.na'i in casual speech. ${ }^{4}$ Goldstein 2001 lists all three forms (p. 1000), but identifies yin.na'ang as the canonical form. I follow this convention here and report all examples with yin.na'ang.

$$
\begin{aligned}
& \text { yin }+ \text { na }+ \text { yang }=\text { yin.na.yang }>\text { yin.na'ang }>\text { yin.na'i } \\
& \text { copula cond even }
\end{aligned}
$$

In addition to forming wh-FCIs, yin.na'ang has two other uses, as a counterexpectational discourse particle - i.e. the translation equivalent for English 'but' and 'however' - and as a concessive scalar particle. I discuss these uses and their compositional semantics in Erlewine 2020.

Here I pursue the null hypothesis, that yin.na'ang in the expression of free choice indeed decomposes into the ingredients in (2). The structure in (1) is thus literally as in (3). Wh-yin.na'ang is a concessive conditional (i.e. even if; see e.g. König 1986) containing a copular description with a wh-word.

Norbu eats [even if $\{$ it/the food $\}$ is what].

My core analytic contribution in this paper will be to show how these ingredients in (3) together give rise to the expression's behavior as a universal FCI, without stipulating universal quantificational force. Previous work has discussed both empirical and analytic connections between universal free choice and (concessive) conditionals, as well as to ever free relatives and so-called unconditionals (see e.g. Gawron 2001; Rawlins 2008a,b, 2013; Szabolcsi 2019; Balusu 2019, 2020). Existing analyses which take the connection between these constructions seriously either stipulate a covert universal quantifier in these constructions (Menéndez-Benito 2005, 2010; Rawlins 2008a,b, 2013) or propose to derive universal force from a strengthening process (Chierchia 2013; Szabolcsi 2019). I argue that universal quantificational force is instead simply a necessary

3 Tibetan also has another copular form, red, with the choice of yin vs red expressing an evidential distinction (Garrett 2001; Tournadre 2008). However, in non-root contexts where evidential distinctions are not expressed, the copula is uniformly yin; most importantly for our purposes, yin is the expected copular form in conditionals (see e.g. Garrett 2001: 254).

4 This reduction to yin.na'i /yin.n $\epsilon$ / follows the common contraction of the scalar particle yang to ya' $i / \mathrm{y} \epsilon /$, common in speech (Tournadre and Sangda Dorje 2003: 409). 
consequence of the semantics of conditionals, the scalar particle 'even,' and the wh-phrase interpreted as a kind of indefinite, in combination.

\section{An Approach to wh-quantification}

I begin by introducing my assumptions regarding the compositional semantics of wh-phrases and their interaction with focus particles such as EvEN. Studies of the semantics of $w h$-questions and focus association have both motivated the idea that natural language meanings may make reference to sets of alternative denotations that vary in a systematic way. In a larger project in progress (see e.g. Erlewine 2019, in prep.), I pursue the hypothesis that these two forms of "alternatives" in grammar can be productively integrated, with the result being a compositional semantics for a wide range of non-interrogative uses of whwords, i.e. wh-quantification. I present the core of this approach here, illustrating through its application to wh-EVEN NPIs in Tibetan (Erlewine and Kotek 2016).

I begin with a brief sketch of the compositional semantics of focus association in the framework of Alternative Semantics (Rooth 1985, 1992). Consider the interpretation of the English example (4) with the focus particle even.

(4) Even Tashi came to the party.

Following Karttunen and Peters 1979, the addition of even here introduces a requirement that the possibility of Tashi coming to the party is somehow particularly unlikely, compared to the possibility of other people coming to the party. ${ }^{5}$

Let us see how this meaning can be computed compositionally. We annotate the position of focus in a sentence with ...F (Jackendoff 1972). As Jackendoff discusses, with even in pre-subject position in English, focus must be on the subject or a subpart thereof. We therefore take the LF structure for (4) to be as in (5a). In Alternative Semantics, each syntactic object $\alpha$ has two different corresponding meanings: its ordinary semantic value, $\llbracket \alpha \rrbracket^{\circ}$, and a set of alternative denotations of equal semantic type, $\llbracket \alpha \rrbracket^{\text {alt }}$. The alternative set $(5 c)$ is a set of propositions that includes the prejacent proposition $(5 \mathrm{~b})$, as well as other contextually restricted alternative propositions that vary in the focused position. Even introduces the inference in (5d), requiring that the prejacent proposition $\llbracket \alpha \rrbracket^{\circ}$ (that Tashi came) be the least likely among the alternatives $\llbracket \alpha \rrbracket^{\text {alt }}$.

\footnotetext{
${ }^{5}$ This scalar requirement is frequently described as a presupposition, but Karttunen and Peters 1979 and Kay 1990 characterize it as a conventional implicature. Here I will simply refer to it as the "scalar inference" and not comment on its precise status, except that it is not at-issue. Karttunen and Peters 1979 also describes an additional, additive inference of even: a requirement that someone else in addition to Tashi came to the party. Here I concentrate on the scalar part of even.
} 

a. LF: EVEN $\left[\alpha[\text { Tashi }]_{F}\right.$ came to the party $]$
b. $\llbracket \alpha \rrbracket^{\mathrm{o}}={ }^{\wedge}$ Tashi came to the party
c. $\llbracket \alpha \rrbracket^{\text {alt }}=\left\{\wedge\right.$ Tashi came..., $\wedge^{\wedge}$ Sonam came..., $\wedge^{\wedge}$ Migmar came..., ... $\}$
d. $[$ EVEN $\alpha] \rightsquigarrow(\wedge$ Tashi came... $)<$ likely $(\wedge$ Sonam came... $) \wedge$ $(\wedge$ Tashi came... $)<_{\text {likely }}\left(\wedge^{\wedge}\right.$ Migmar came... $) \ldots$

The general recipe for this scalar inference of even is given in (6a). Even simply passes up the ordinary value of its complement (6b); thus in (5), the at-issue content is the prejacent proposition, 'that Tashi came to the party.'

\section{The contribution of even:}
a. $[\operatorname{EVEN} \alpha] \rightsquigarrow \forall q \in \llbracket \alpha \rrbracket^{\text {alt }}\left[q \neq \llbracket \alpha \rrbracket^{\mathrm{o}} \rightarrow \llbracket \alpha \rrbracket^{\mathrm{o}}<\right.$ likely $\left.q\right]$
b. $\llbracket \operatorname{EVEN} \alpha \rrbracket^{\mathrm{o}}=\llbracket \alpha \rrbracket^{\mathrm{o}}$
c. $\quad \llbracket \operatorname{EVEN} \alpha \rrbracket^{\text {alt }}=\left\{\llbracket \alpha \rrbracket^{\mathrm{o}}\right\}$

Finally, even also has the function of "resetting" the alternative set to be the singleton set of the ordinary value $(6 \mathrm{c})$.

Let's now step back and discuss the computation of ordinary and alternative set denotations. Just as ordinary denotations of complex expressions are determined by the denotations of their subparts (7a), where $\circ$ is the appropriate mode of composition (e.g. functional application), Alternative Semantics provides a procedure for calculating the alternative set denotation for a complex expression, in $(7 \mathrm{~b})$.

(7) For node $\alpha$ with two daughters, $\beta$ and $\gamma$ :
a. $\llbracket \alpha \rrbracket^{\mathrm{o}} \equiv \llbracket \beta \rrbracket^{\mathrm{o}} \circ \llbracket \gamma \rrbracket^{\mathrm{o}}$
b. $\llbracket \alpha \rrbracket^{\text {alt }} \equiv\left\{b \circ c \mid b \in \llbracket \beta \rrbracket^{\text {alt }}, c \in \llbracket \gamma \rrbracket^{\text {alt }}\right\}$

In words, for $\alpha$ with two daughters $\beta$ and $\gamma$, each alternative denotation for $\beta$ is composed with each alternative denotation for $\gamma$; the collection of such results is the alternative set denotation for $\alpha$.

This method for the computation of sets of alternatives in (7b) is also useful for the interpretation of in-situ wh-phrases, as was proposed earlier in Hamblin 1973. Wh-phrases have the denotation of a set of alternatives, which then compose pointwise with other material to yield the denotation of a question as a set of alternative propositions, corresponding to possible answers. I follow Ramchand 1996, 1997, Beck 2006, and Kotek 2014, 2019, in casting this Hamblinian system of wh-alternatives within the Roothian two-dimensional semantic system just presented. Wh-phrases have an alternative set denotation corresponding to its Hamblin alternatives, but no defined ordinary semantic value. See for example the denotation of who in (8); its alternative set (8b) is the set of contextuallydetermined animate individuals which may count as short answers to who.
a. $\llbracket$ who $\rrbracket^{\mathrm{o}}$ undefined
b. $\llbracket$ who $\rrbracket^{\text {alt }}=\{$ Tashi, Sonam, Migmar, ... $\}$ 
Consider now the interpretation of the Tibetan wh-containing clause in (9) below. This example must be interpreted as a wh-question, even without the final question marker gas. Tibetan is a wh-in-situ language and does not have bare $w h$-indefinites.

Tibetan wh-question:

[TP Thugs.spro-la su slebs-song] (-gas?)

party-DAT who arrive-AUX -Q

'Who came to the party?' / *'Someone came to the party.'

Composing 'who' (8) with the rest of the clause, we yield (10):

a. $\llbracket \mathrm{TP} \rrbracket^{\circ}$ undefined

b. $\quad \llbracket \mathrm{TP} \rrbracket^{\text {alt }}=\left\{\wedge\right.$ Tashi came..., ${ }^{\wedge}$ Sonam came..., ${ }^{\wedge}$ Migmar came, ... $\}$

To grammatically interpret (10) as a question, the alternatives that have been calculated as an alternative set $\left(\llbracket \mathrm{TP} \rrbracket^{\text {alt }}\right)$ must be made the ordinary semantic value, which is the denotation that is ultimately interpreted. This is accomplished by the interrogative complementizer (Beck 2006) or by a dedicated adjoined operator, AltShift (Kotek 2019). See especially Kotek 2019 for more on the use of this framework for the interpretation of wh-questions.

Our interest, however, is in the non-interrogative use of $w h$-phrases, especially in concert with focus particles. In addition to wh-yin.na'ang FCIs, Tibetan forms NPIs through the combination of a wh-phrase and the scalar particle yang 'even' (Erlewine and Kotek 2016), as in (11):

\section{Wh-even NPI:}

Thugs.spro-la su-yang slebs-*$^{*}(\mathbf{m a})$-song. party-DAT who-EVEN arrive-NEG-AUX

'No one came to the party.'

Let's consider the interpretation of the grammatical (with negation) and ungrammatical (negation-less) variants of (11) in turn. Following Erlewine and Kotek 2016, I take the focus particle yang to correspond to a unary EVEN operator taking propositional scope at LF, as schematized in (12). ${ }^{6}$ When we attempt to compute the EVEN in this structure, however, we run into a problem. The semantics for the scalar inference of EVEN (6a) requires that its sister have a defined ordinary value, but the sister of EVEN in (12) is a wh-containing clause, as in (10), and therefore does not have a defined ordinary value.

\footnotetext{
${ }^{6}$ See also Branan and Erlewine 2020 for further discussion of this approach to constituent focus particles, as well as a supporting data point from Tibetan.
} 


\section{LF: EVEN [NEG [ who came to the party ] ]}

To avoid this issue, I propose the adjunction of a covert operator $\exists$ (13) that defines an ordinary value that is the disjunction of its sister's alternative set, and simply passes up its sister's alternative set as its own. ${ }^{7,8}$

$$
\begin{array}{ll}
\text { a. } & \llbracket \exists \alpha \rrbracket^{\mathrm{o}}=\bigvee \llbracket \alpha \rrbracket^{\text {alt }} \\
\text { b. } & \llbracket \exists \alpha \rrbracket^{\text {alt }}=\llbracket \alpha \rrbracket^{\text {alt }}
\end{array}
$$

The full LF for (11) is thus as follows in (14). The denotation for (1) is as in (10), which has no defined ordinary value. The application of $\exists$ in (2) results in (14a). Negation applies pointwise in (3) (14b). Now notice that $\llbracket\left(3 \rrbracket^{\circ}\right.$ asymmetrically entails every alternative in $\llbracket(3) \rrbracket^{a l t}$. This ensures that the scalar inference of EVEN (14c) will always be true. The end result will be equivalent to the proposition 'that no one came to the party,' as desired.

LF: EVEN [3 NEG [(2) $\exists$ [1(1) who came to the party ] ] ]

a. i. $\llbracket\left(2 \rrbracket^{\circ}={ }^{\wedge}\right.$ Tashi or Sonam or Migmar... came to the party $=\wedge$ someone came to the party

ii. $\llbracket(2) \rrbracket^{\text {alt }}=\llbracket(1) \rrbracket^{\text {alt }}=\left\{\wedge \mathrm{T}\right.$ came..., $\wedge^{\wedge} \mathrm{S}$ came..., $\wedge^{\wedge} \mathrm{M}$ came..., ... $\}$

b. i. $\llbracket(3) \rrbracket^{\mathrm{o}}=\operatorname{NEG}\left({ }^{\wedge}\right.$ someone came to the party $)$

$=\wedge$ no one came to the party

ii. $\llbracket\left(3 \rrbracket^{a l t}=\left\{\wedge^{\mathrm{T}}\right.\right.$ didn't come..., ${ }^{\wedge} \mathrm{S}$ didn't come..., ${ }^{\wedge} \mathrm{M}$ didn't..., ... $\}$

c. [EVEN (3] $\rightsquigarrow\left(\wedge\right.$ no one came...) $<_{\text {likely }}\left(\wedge^{\wedge}\right.$ T didn't come... $) \wedge$

$\left(\wedge^{\wedge}\right.$ no one came...) $<$ likely $\left({ }^{\wedge} \mathrm{S}\right.$ didn't come...) $\wedge$

$\left(\wedge^{\wedge}\right.$ no one came... $)<$ likely $\left({ }^{\wedge} \mathrm{M}\right.$ didn`t come...) ...

Now consider the variant of this structure without negation. (15) gives the scalar inference predicted by EVEN applying directly to (2) in (14a):

$$
\begin{aligned}
\text { [EVEN (2] } \rightsquigarrow & \left(\wedge \text { someone came...) }<\text { likely }\left({ }^{\wedge} \text { Tashi came... }\right) \wedge\right. \\
& \left(\wedge \text { Someone came...) }<\text { likely }\left({ }^{\wedge} \text { Sonam came... }\right) \wedge\right. \\
& (\wedge \text { someone came... })<\text { likely }\left({ }^{\wedge} \text { Migmar came... }\right) . .
\end{aligned}
$$

Because the prejacent 'that someone came to the party' 【(2) $\rrbracket^{\circ}$ is asymmetrically entailed by each alternative in $\llbracket\left(2 \rrbracket^{a l t}\right.$, this requirement in (15) is a contradiction. This scalar inference of EvEN can never be satisfied. Following Lahiri 1998, this

\footnotetext{
${ }^{7}$ For Erlewine and Kotek 2016, this function is served by the additive component of EVEN, in lieu of this covert $\exists$ operator. In Erlewine 2019, in prep., I argue for the use of this $\exists$ operator for $w$-quantification in a range of languages and contexts, beyond those with additive particles.

8 This $\exists$ operator stands in contrast to the existential closure operator of e.g. Kratzer and Shimoyama 2002, which also has the effect of collapsing or "resetting" the set of alternatives, leading to the predicted availability of bare wh indefinites, contrary to fact; see (9). In contrast, the $\exists$ operator defined here in (13) results in a structure that necessitates association with a higher operator which will "reset" the alternative set. See Erlewine 2019, in prep. for further discussion.
} 
fatal requirement of EVEN in (15) leads to the ungrammaticality of the wh-EVEN expression without a licensing negation. ${ }^{9}$

In this way, the Hamblin semantics of wh-phrases can be productively combined with the Roothian semantics of focus, for example giving us a compositional semantics for wh-EVEN NPIs in Tibetan. With this background on the compositional semantics of $w h$-phrases and their interaction with focus particles in place, we are now in a position to turn to the compositional semantics of wh-yin.na'ang FCIs.

\section{On the Syntax of wh-yin.na'ang}

Next I address the syntax of wh-yin.na'ang FCIs. I first address its external syntax - how the wh-yin.na'ang expression relates to its containing clause - and then its internal syntax - i.e. the nature of the copular relation.

Taking its morphology at face value, wh-yin.na'ang is a wh-containing conditional clause, to which the scalar focus particle yang has adjoined, and I propose that it is interpreted as such. However, there is evidence that this whole FCI structure may actually occupy a nominal argument position. Consider example (16). Here the wh-yin.na'ang FCI hosts the dative case marker -la:

Wh-yin.na'ang FCI with dative case:
Pad.ma $\frac{[(\mathrm{phru.gu}) \text { su yin.na'ang]-la }}{\text { skad.cha bshad-kyi-red. }}$
Pema child who YIN.NA'ANG-DAT speech talk-IMPF-AUX
'Pema talks to anyone / any child.'

The wh-yin.na'ang FCI is a clause in an argument position which describes that argument, and thus in broad strokes resembles a head-internal relative clause or a so-called amalgam structure (Lakoff 1974; also Kluck 2011), as in (17):

John is going to I think it's Chicago on Saturday.

(Lakoff 1974: 324)

Here I propose to follow an intuition developed by Shimoyama (1999) for the interpretation of Japanese head-internal relatives, and independently by Hirsch (2016) for English ever free relatives. This idea is that the embedded clause is interpreted higher at LF, as adjoined to the embedding clause, and that the argument position is then interpreted as a pronoun anaphoric to an individual described in the clause. ${ }^{10}$ As a concrete example, then, assuming a surface structure for (16) roughly isomorphic to (18a) below, the corresponding LF for its interpretation will resemble $(18 \mathrm{~b})$.

\footnotetext{
${ }^{9}$ Erlewine and Kotek 2016 shows that wh-EvEN NPIs in Tibetan must be licensed by clause-mate negation. This is explained by the interpreted LF position of EVEN needing to be in the same clause as the pronounced position of yang. See Erlewine and Kotek 2016: 149 for discussion.

10 The informal coindexation in (18) will be formalized in terms of equality of nominal descriptions in Sect. 4 below.
} 


\section{The structure of wh-yin.na'ang:}

a. Literal (16): Pema talks to [even if $\{$ it/the child $\}$ is who] $\Rightarrow$

b. LF: [even if $\{\text { it/the child }\}_{\mathrm{i}}^{\prime} s$ who], Pema talks to them $_{\mathrm{i}} \Rightarrow$ EVEN [if $\{\text { it/the child }\}_{\mathrm{i}}^{\prime} s$ who, Pema talks to them ${ }_{\mathrm{i}}$ ]

I model the scalar particle yang as a unary EVEN operator at LF (Erlewine and Kotek 2016; see footnote 6), taking the entire conditional structure, with its consequent clause, as its complement. This is reflected in (18b) above.

Next, we turn to the internal syntax of wh-yin.na'ang. Again, following the overt morphology, I take the antecedent of the conditional to be a copular description involving a wh-phrase. I will suggest here that, within the Higgins 1973 classification of copular clauses, this is (in many cases) a specificational copular clause. Specificational copular clauses are distinguished through their information structure and use as well as in their syntax; for instance, pronominal reference to specificational subjects involve the neuter pronoun, as in (19a):

a. Specificational copular clause:

The tallest girl in the class is Molly, isn't it/*she?

(Mikkelsen 2005: 72)

b. Predicational copular clause:

The tallest girl in the class is Swedish, isn't she/*it?

Mikkelsen and subsequent authors have taken such facts to reflect that the subject of a specificational copular clause is not a referential expression of type e. In particular, Romero 2005 proposes that (definite) specificational subjects are individual concepts (functions from worlds to individuals); see also Arregi, Francez, and Martinovic to appear for recent support. As individual concepts, (definite) specificational subjects will not impose a uniqueness requirement for the nominal restriction on the evaluation world, although they will impose a uniqueness requirement on the referent given a particular evaluation world or situation. We will return to this detail, as well as discussion of indefinite specificational subjects, in Sect.5.3.

In cases such as (16) with explicit nominal domain phru.gu 'child' or (1) above with kha.lag 'food,' I take these nominals to be the first argument, or the "subject," of the specificational copula. In the absence of such a nominal, I posit a corresponding null nominal (pro) as the first argument. The second argument of the copula is the wh-word whose alternative set ranges over individuals of type $e$, de re. ${ }^{11}$ This discussion thus motivates the informal, literal translation of the specificational copular clauses using the English ' $\{$ it/the child $\}$ is who' in (18b) or ' $\{$ it/the food $\}$ is what' for (1).

An alternative analysis would be for these nominals to form a constituent with the $w h$-word to form a complex wh-phrase. However, complex wh-phrases in Tibetan are headed by postnominal ga.gi 'which' and wh-yin.na'ang FCIs cannot be built from such which-phrases:

${ }^{11}$ I limit the discussion here to the wh-words $s u$ 'who' and ga.re 'what' and leave discussion of other wh-words in FCIs for future work. 


\section{Wh-yin.na'ang does not take which-phrases:}
a. *[kha.lag ga.gi] yin.na'ang food which YIN.NA'ANG 'any (of the) food'
b. *[phru.gu ga.gi] yin.na'ang child which YIN.NA'ANG 'any child / of the children'

Therefore, I argue that the copular verb takes the noun phrase - or if absent, a corresponding null nominal - and the $w$ h-word as two separate arguments.

\section{Interpreting wh-yin.na'ang}

With these preliminaries in place, we now turn to the compositional semantics of wh-yin.na'ang. As discussed above, yin.na'ang is a transparent combination of the copular verb yin, conditional suffix $n a$, and scalar particle yang 'even,' in an amalgam-like argument position. In this section, I will show how these ingredients (even without considering 'even') together in the examples presented above yield a universal free choice expression. In particular, my approach does not need to stipulate the universal force for these expressions as in MenéndezBenito 2005, 2010 or Rawlins 2008a,b, 2013, nor derive universal force from a secondary strengthening process as in Chierchia 2013 and Szabolcsi 2019.

Once we have established how universal force comes about in these grammatical examples, in Sect.5, I show how this construction enforces universal force. There, yang 'even' will play a star role. Just as association with 'even' can build NPIs from indefinites (Lee and Horn 1995; Lahiri 1998), as we also saw in Tibetan in Sect.2, the logical properties of 'even' will serve to ensure that wh-yin.na'ang be interpreted as a universal FCI.

Recall that Tibetan wh-yin.na'ang FCIs may be in argument positions. ${ }^{12}$ I proposed in Sect. 3 above that a FCI in argument position is interpreted at LF as a conditional clause adjoined to the containing clause, with unary EVEN taking the entire conditional structure as its sister.

The structure of wh-yin.na'ang in (16): based on (18)

a. Surface stucture: Pema talks to [even if $\{$ pro/the child $\}$ is who] $\Rightarrow$

b. LF: EVEN [ if $\left[_{\phi} \exists\left[\{\text { pro/the child }\}_{\mathrm{i}}\right.\right.$ is who $\left.]\right]$,

$\left[\psi\right.$ IMPF [ Pema talks to pro $\left.\left.\left._{\mathrm{i}}\right]\right]\right]$

The $\exists$ operator in (21b) is the covert operator discussed in Sect. 2 above. Note that $\phi$ is a $w h$-containing clause, and thus without the insertion of $\exists$, the sister of EVEN would have no defined ordinary value (prejacent) and thus the result would be uninterpretable at $\mathrm{LF}$.

As discussed in Sect. 3 above, the antecedent of the conditional $\phi$ is a specificational copular clause. I adopt the view that the subjects of specificational

${ }^{12}$ I suspect that they are always in argument positions, but in the absence of overt case markers or postpositions as in (16), it is difficult to be certain. For examples without such clues, it is possible that wh-yin.na'ang is overtly in its clausal adjunct position, as in (21b), with the corresponding pronoun in the consequent clause simply being null. Note that Tibetan is descriptively pro-drop. 
copular clauses are individual concepts (Romero 2005). Individual concepts are functions of type $\langle s, e\rangle$ from worlds or situations to individuals. Situations are subparts of possible worlds, which may be thought of as limited to particular times or places (see e.g. Kratzer 1989; Heim 1990). The type $s$ is used for all situations, including worlds, which are simply maximal situations.

Concretely, I assume that these specificational subjects as in (21b) involve a definite determiner as in (22), taken from Elbourne's work on definite descriptions in situation semantics. As Tibetan is an article-less language, I assume that THE is unpronounced. Composing THE with a nominal property such as 'child' in (23) yields the individual concept denotation in (24) of type $\langle s, e\rangle$.

$$
\begin{aligned}
& \llbracket \mathrm{THE} \rrbracket=\lambda P_{\langle e,\langle s, t\rangle\rangle} \cdot \lambda s: \exists ! x[P(x)(s)] . \iota x[P(x)(s)] \quad \text { (Elbourne 2013: 35) } \\
& \llbracket \text { child } \rrbracket=\lambda x \cdot \lambda s_{s} . x \text { is a child in } s \\
& \llbracket \mathrm{THE} \text { child } \rrbracket=\lambda s: \exists ! x[x \text { child in } s] . \iota x[x \text { child in } s]
\end{aligned}
$$

Individual concepts of this form will be undefined for world/situations where the property's extension is not unique.

In cases with no nominal restrictor, I assume a corresponding null nominal (indicated as pro in (21b) above) which refers to a contextually salient property $P$, and which we can informally describe as "THE $P$." Below, I will refer to this salient property as $P$ in the general case, whether pronounced or not.

$$
\llbracket \text { THE } P \rrbracket=\lambda s_{s}: \exists ! x[P(x)(s)] . \iota x[P(x)(s)]
$$

As proposed in Sect. 3, in LFs for wh-yin.na'ang FCIs, there is a pronoun in FCI's surface argument position which is related to the subject of the conditional clause in some way. I used co-indexation above as in "pro ${ }_{\mathrm{i}} \ldots$ pro $_{\mathrm{i}}$ " as a notational device to highlight the link between these two nominals, but we are now in a position to specify this relationship. Specifically, I propose that these two positions refer to the same individual concept: "THE $P$." In the antecedent clause $\phi$, "THE $P$ " is the specificational subject. In the consequent clause $\psi$, "THE $P$ " is evaluated with respect to $\psi$ 's situation or world of evaluation. We can restate the structure in (21b) in these terms as follows:

\section{LF for (16):}

(revised from $(21 b)$ )

EVEn [ if $\left[{ }_{\phi} \exists[\operatorname{THE} P\right.$ is who $\left.]\right],[\psi \operatorname{IMPF}[$ Pema talks to THE $\left.P]]\right]$

I now turn to the compositional semantics of this LF, beginning with the antecedent of the conditional, $\phi$. Given the semantics for 'who' (8) and $\exists$ (13) above, we yield the following two-dimensional denotation for $\phi$ in (26):

\section{$\phi$ in (26):}

a. $\llbracket \phi \rrbracket^{\mathrm{o}}=\lambda s_{s}: \exists ! x[P(x)(s)]$

$$
. \iota x[P(x)(s)]=\text { Tashi } \vee \iota x[P(x)(s)]=\text { Sonam } \vee \ldots
$$

b. $\llbracket \phi \rrbracket^{\text {alt }}=\left\{\begin{array}{l}\lambda s_{s}: \exists ! x[P(x)(s)] . \iota x[P(x)(s)]=\text { Tashi, } \\ \lambda s_{s}: \exists ! x[P(x)(s)] . \iota x[P(x)(s)]=\text { Sonam }, \ldots\end{array}\right\}$

The ordinary value of $\phi(27 \mathrm{a})$ is a proposition - a predicate of situations - which presupposes that there is a unique $P$-individual in its argument situation $s$ and 
will return true if that individual is Tashi or Sonam or Migmar, etc.; e.g. in the domain of 'who.' The individual alternatives in $\llbracket \phi \rrbracket^{\text {alt }}(27 \mathrm{~b})$ each similarly presuppose a unique $P$-individual in the situation, but then return true when it is a particular individual in the domain.

We now turn to the interpretation of the conditional and its consequent $\psi$. I adopt the now standard approach to conditionals as restricting the domain of a modal or temporal operator in the consequent clause (Lewis 1975; Kratzer 1979, 1986; von Fintel 1994). The modal/temporal operator in the consequent $\psi$ (the overt main clause) in both examples that we have seen so far (in (1) and (16)) is the imperfective aspect with generic/habitual interpretation. Following Arregui, Rivero, and Salanova 2014 and citations there, I model the imperfective as a type of universal modal that quantifies over a particular set of situations. In particular, for generic or habitual imperfectives, in turn following Cipria and Roberts 2000, the relevant set of situations will be "normal or usual" sub-situations of the topic situation, formally described as "characteristic" (Cipria and Roberts 2000: 325). I write $s^{\prime} \leq_{c h} s$ to indicate that $s^{\prime}$ is a characteristic sub-situation of $s$.

I spell out the interpretation of $\psi$ with its imperfective quantification in (28). As $\psi$ does not contain any alternative-generating (e.g. focused or wh) expression, $\llbracket \psi \rrbracket^{\text {alt }}=\left\{\llbracket \psi \rrbracket^{\mathrm{o}}\right\}$.

$$
\begin{aligned}
& \psi \text { in (26): } \\
& \llbracket \psi \rrbracket^{\mathrm{o}}=\mathrm{IMPF}_{\text {habitual }}\left(\llbracket \text { Pema talks to THE } P \rrbracket^{\mathrm{o}}\right) \\
& =\lambda s_{s} . \forall s^{\prime}\left[s^{\prime} \leq_{c h} s \rightarrow \text { Pema talks to THE } P \text { in } s^{\prime}\right] \\
& =\lambda s_{s} . \forall s^{\prime}\left[s^{\prime} \leq_{c h} s \wedge \exists ! x\left[P(x)\left(s^{\prime}\right)\right] \rightarrow \text { Pema talks to } \iota x\left[P(x)\left(s^{\prime}\right)\right] \text { in } s^{\prime}\right]
\end{aligned}
$$

Note that, in the third line in (28), I have unpacked the definedness requirement of "THE $P$ " and allowed this condition to restrict the set of relevant sub-situations $s^{\prime}$. For example, if $P$ is 'child,' we are allowing ourselves to look at only those characteristic sub-situations where there is a unique child to refer to. ${ }^{13}$ In all such situations, Pema talks to that child.

We now can calculate our full conditional clause, "if $\phi, \psi$." Recall that the conditional clause $\phi$ acts as a restrictor on the modal base of the $\psi$ 's modal quantification. The two-dimensional denotation for "if $\phi, \psi$ " is thus as in (29). The effects of this conditional restriction are boxed here for presentation:

"If $\phi, \psi$ " in (26):

$$
\begin{aligned}
& \text { a. } \quad \text { if } \phi, \psi \rrbracket^{\circ}=\lambda s_{s} . \forall s^{\prime}\left[\begin{array}{c}
s^{\prime} \leq \text { ch } s \wedge \exists ! x\left[P(x)\left(s^{\prime}\right)\right] \\
\wedge \llbracket \phi \rrbracket^{\circ}\left(s^{\prime}\right)
\end{array} \rightarrow \begin{array}{c}
\text { Pema talks to } \\
\iota x\left[P(x)\left(s^{\prime}\right)\right] \text { in } s^{\prime}
\end{array}\right] \\
& =\lambda s_{s} \cdot \forall s^{\prime}\left[\begin{array}{c}
s^{\prime} \leq \text { ch } s \wedge \exists ! x\left[P(x)\left(s^{\prime}\right)\right] \\
\wedge\left(\begin{array}{l}
\iota x\left[P(x)\left(s^{\prime}\right)\right]=\mathrm{T} \vee \\
\iota x\left[P(x)\left(s^{\prime}\right)\right]=\mathrm{S} \vee \ldots
\end{array}\right)
\end{array} \rightarrow \begin{array}{c}
\text { Pema talks to } \\
\iota x\left[P(x)\left(s^{\prime}\right)\right] \text { in } s^{\prime}
\end{array}\right]
\end{aligned}
$$

13 A reviewer raises a concern about this presupposition in the modal prejacent affecting the set of situations that we quantify over. This can be thought of as a more general effect, where the description in the modal prejacent affects the domain of quantification chosen, as discussed by Arregui et al. (2014: 318). 
b. $\quad$ if $\phi, \psi \rrbracket^{\text {alt }}=\left\{\begin{array}{cc}\lambda s_{s} \cdot \forall s^{\prime}\left[\begin{array}{cc}s^{\prime} \leq c h s \wedge \exists ! x\left[P(x)\left(s^{\prime}\right)\right] & \text { Pema talks to } \\ \wedge \iota x\left[P(x)\left(s^{\prime}\right)\right]=\text { Tashi } & \rightarrow x\left[P(x)\left(s^{\prime}\right)\right] \text { in } s^{\prime}\end{array}\right], \\ \lambda s_{s} \forall s^{\prime}\left[\begin{array}{cc}s^{\prime} \leq c h s \wedge \exists ! x\left[P(x)\left(s^{\prime}\right)\right] \\ \wedge \iota x\left[P(x)\left(s^{\prime}\right)\right]=\text { Sonam }\end{array} \rightarrow \begin{array}{c}\text { Pema talks to } \\ \iota x\left[P(x)\left(s^{\prime}\right)\right] \text { in } s^{\prime}\end{array}\right],\end{array}\right\}$

The final ingredient in the wh-yin.na'ang LF in (26) is EVEN. As EVEN does not change the at-issue (asserted) content, our work in interpreting example (16) is now done, in (29a). (I discuss the contribution of EVEN in the following section.) What does this result in (29a) express? It claims that, in all characteristic sub-situations $s^{\prime}$ of the topic situation $s$ where (a) there is a unique $P$ (e.g. 'child') in $s^{\prime}$ and (b) that unique $P$ is Tashi or Sonam or Migmar, etc.- e.g., an individual in the domain of 'who'-Pema talks to that unique $P$.

Let's restate this again in slightly more informal terms, to build an intuition for the claim. Concretely, let our salient property $P$ be 'child,' and assume that all individuals that satisfy 'child' are in the domain of 'who.' Then, (29a) conveys the following:

(30) In any and all "normal or usual" sub-parts of the current situation/world with a unique child, Pema talks to that child.

Note that (30) does not require Pema to have actually spoken with any or all of these children. Instead, it uses the modal semantics of the imperfective to allow ourselves to consider different "characteristic" situations with different children present. What about a situation with Tashi? Pema talks to him. How about Sonam? Pema talks to her too. Pema talks to any child. We have successfully derived the expression of universal free choice.

How did we do this? In particular, where did the universal force of the FCI come from? The universal quantificational force of wh-yin.na'ang in this example is that of the imperfective modal/temporal operator, whose modal base was restricted by the conditional. The imperfective introduces universal quantification over situations (see e.g. Arregui et al. 2014), with a shared individual concept evaluated in both the conditional and its prejacent, allowing us to indirectly universally quantify over different individuals in different situations. ${ }^{14} \mathrm{On}$ this approach, this universal force need not be stipulated as in Menéndez-Benito 2005, 2010 or Rawlins 2008a,b, 2013, nor does it need to be derived using a strengthening procedure as in Chierchia 2013 and Szabolcsi 2019. Instead, it is simply a reflection of an ingredient that is already there: the modal/temporal operator restricted by the conditional.

14 There are a number of precursors to this idea - see for example Giannakidou 2001: 665-666 and citations there - although the implementation here using situationbinding in conditionals is to my knowledge new. In addition, the idea that 'even' plays a critical role in enforcing universal force, which I develop in the next section, is also new. 


\section{Restricting the Distribution of wh-yin.na'ang}

In the previous section, we saw how the wh-yin.na'ang FCI derives the effect of universal quantification over a set of individuals, parasitic on a universal modal/temporal quantifier in the sentence. In this section, I discuss two principled ways in which the use and interpretation of wh-yin.na'ang is restricted. First, I discuss the role of the scalar particle yang 'even' in ensuring the FCI's universal quantificational force. Second, I discuss the incompatibility of whyin.na'ang in necessity statements and episodic descriptions, and offer a new intuition for the nature of so-called subtrigging effects (LeGrand 1975).

\subsection{Enforcing Universal Force}

I begin by discussing the role of yang 'even' in enforcing the universal quantificational force of wh-yin.na'ang. First, we consider the effect of EVEN in example (16), which applies last in its LF (26). I repeat the two-dimensional denotation of EVEN's sister, "if $\phi, \psi$," here blurring out the material that is common to all propositions, so we can more easily see their interrelationships.

"If $\phi, \psi$ " from (29), schematically:

a. $\quad \llbracket$ if $\phi, \psi \rrbracket^{\mathrm{o}}=\lambda s_{s} . \forall s^{\prime}\left[\ldots \wedge\left(\begin{array}{l}\iota x\left[P(x)\left(s^{\prime}\right)\right]=\text { Tashi } \vee \\ \iota x\left[P(x)\left(s^{\prime}\right)\right]=\text { Sonam } \vee \ldots\end{array}\right) \rightarrow \ldots\right]$

b. $\quad \llbracket$ if $\phi, \psi \rrbracket^{\text {alt }}=\left\{\begin{array}{l}\lambda s_{s} \cdot \forall s^{\prime}\left[\ldots \wedge \iota x\left[P(x)\left(s^{\prime}\right)\right]=\text { Tashi } \rightarrow \ldots\right] \\ \lambda s_{s} . \forall s^{\prime}\left[\ldots \wedge \iota x\left[P(x)\left(s^{\prime}\right)\right]=\text { Sonam } \rightarrow \ldots\right], \ldots\end{array}\right\}$

We observe that the ordinary value 【if $\phi, \psi \rrbracket^{\circ}(31 \mathrm{a})$ asymmetrically entails each of the alternatives in 【if $\phi, \psi \rrbracket^{\text {alt }}(31 \mathrm{~b})$ : If "in every situation where the unique $P$ is Tashi or Sonam or ..., blah is true," then it follows that "in every situation where the unique $P$ is Tashi, blah," and "in every situation where the unique $P$ is Sonam, blah," etc., but not vice versa. The prejacent proposition of EVEN is necessarily less likely than all of its alternatives, so the scalar inference of [EVEN [if $\phi, \psi]$ ] will always be true. The addition of EVEN is felicitous here. ${ }^{15}$

What happens if the conditional instead restricts an existential modal/temporal quantifier, e.g. a possibility modal, instead of the universal imperfective operator of the examples above? Schematically again, we can expect to yield denotations for "if $\phi, \psi$ " of the form in (32). The salient change from (31) is boxed.

$\overline{15}$ This appears to make the addition of yang in wh-yin.na'ang systematically vacuous. In Erlewine 2019, in prep., I suggest that this is not entirely so: The addition of an overt focus particle necessitates its sister to have a defined ordinary value, which licenses insertion of the $\exists$ operator (13), whose insertion is otherwise marked. 


\section{"If $\phi, \psi "$ with $\phi$ restricting a possibility modal in $\psi$ :}

a. $\quad$ if $\phi, \psi \rrbracket^{\mathrm{o}}=\lambda s_{s} \cdot \exists s^{\prime}\left[\ldots \wedge\left(\begin{array}{l}\iota x\left[P(x)\left(s^{\prime}\right)\right]=\text { Tashi } \vee \\ \iota x\left[P(x)\left(s^{\prime}\right)\right]=\text { Sonam } \vee \ldots\end{array}\right) \wedge \ldots\right]$

b. $\quad \llbracket$ if $\phi, \psi \rrbracket^{\text {alt }}=\left\{\begin{array}{l}\lambda s_{s} \cdot \exists s^{\prime}\left[\ldots \wedge \iota x\left[P(x)\left(s^{\prime}\right)\right]=\text { Tashi } \wedge \ldots\right], \\ \lambda s_{s} \cdot \exists s^{\prime}\left[\ldots \wedge \iota x\left[P(x)\left(s^{\prime}\right)\right]=\text { Sonam } \wedge \ldots\right], \ldots\end{array}\right\}$

Here, with existential quantification over situations, the entailment relationships between the prejacent and its alternatives have reversed. Each alternative in $\llbracket$ if $\phi, \psi \rrbracket^{\text {alt }}(32 \mathrm{~b})$ now asymmetrically entails the prejacent $\llbracket$ if $\phi, \psi \rrbracket^{\mathrm{o}}(32 \mathrm{a})$ : If any proposition of the form "there is a situation where the unique $P$ is Tashi, and blah is true" or "there is a situation where the unique $P$ is Sonam, and blah is true" etc. is true, it follows that "there is a situation where the unique $P$ is Tashi or Sonam or... and blah is true" will necessarily be true. In this case, the prejacent is logically weaker than its alternatives. EVEN applied to "if $\phi, \psi$ " with a possibility modal will thus lead to a systematically unsatisfiable scalar inference, resulting in ungrammaticality.

The scalar particle yang 'even' in Tibetan wh-yin.na'ang FCIs thus plays a crucial role in ensuring that wh-yin.na'ang always expresses universal free choice, just as it may serve a crucial role in explaining the distribution of NPIs (see e.g. Lee and Horn 1995; Lahiri 1998; Erlewine and Kotek 2016). The logical requirements of EVEN - quantifying over the prejacent and its alternatives using the independently motivated semantics of $w h$-alternatives and their disjunction by $\exists$, introduced in Sect. 2 - ensures that the conditional clause of wh-yin.na'ang restricts a universal modal/temporal operator, and therefore that wh-yin.na'ang itself will always have universal force.

Practically, wh-yin.na'ang does cooccur with possibility modals, as in example (33) below. The verb form in this example differs from (1) in the addition of the deontic possibility modal chog, and is also grammatical. The interpretation of wh-yin.na'ang here is again a universal FCI.

$$
\begin{aligned}
& \text { Wh-yin.na'ang FCI with deontic possibility modal: } \\
& \text { Nga-'i khyi [(kha.lag) ga.re yin.na'ang] za-chog-gi-red. } \\
& \text { 1sg-GEN dog food what YIN.NA'ANG eat-ALLOWED-IMPF-AUX } \\
& \text { 'My dog is allowed to eat anything / any food.' }
\end{aligned}
$$

In such examples, there is in principle a choice as to which modal/temporal operator the conditional clause restricts. If the conditional of wh-yin.na'ang restricts the ability modal, we yield prejacent and alternative set denotations of the form in (32), leading to ungrammaticality due to an unsatisfiable scalar inference of EVEN. Instead, the conditional clause must be construed as restricting the modal base of the higher imperfective operator, leading to the attested meaning where universal free choice takes scope over the possibility modal. 


\subsection{On the Granularity of Modal Quantification}

The approach to universal free choice presented here may at first glance lead us to predict the availability of wh-yin.na'ang FCIs in sentences with any universal modal/temporal operator, whereas in reality its distribution is further restricted. For example, the use of wh-yin.na'ang with the deontic necessity modal dgos is judged as highly marked, just as its intended translation in English is as well.

\section{Wh-yin.na'ang unavailable in necessity statements: \\ ?? Khyed.rang [sman ga.re yin.na'ang] za-dgos-red. \\ 2sg medicine what YIN.NA'ANG eat-must-AUX \\ Intended: $\approx$ 'You must take any medicine.'}

Following the presentation in Sect. 4 above, we predict (34) to have an LF representation as in (35) below. In every deontically best accessible world, where the unique medicine is $x$, you take $x$.

\section{LF for (34):}

EVEN [ if [ $\exists$ [ THE medicine is what ] ], MUST [ you eat THE medicine ] ]

The problem with $(34 / 35)$, I suggest, is a conflict between the granularity of the modal quantification and the uniqueness requirement of the definite individual concept "THE medicine." Specifically, I take the modal MUST here to quantify over possible worlds that are best according to an ordering source. The ordering source introduces considerations of what ought to be done in particular cases, but it does not change facts of the world, such as the uniqueness of medicine. In each world of evaluation, the uniqueness requirement is not satisfied, and thus the sentence cannot be evaluated. ${ }^{16}$ In contrast, in the grammatical examples above, the conditional in wh-yin.na'ang restricted the domain of quantification over a set of situations which could be granular enough to be restricted to situations with unique $P$-individuals.

A similar analysis applies to episodic descriptions, which is another context where wh-yin.na'ang FCIs are unavailable. See example (36) and a grammatical, FCI-less baseline in (37).

$$
\begin{aligned}
& \text { Wh-yin.na'ang ungrammatical in episodic descriptions: } \\
& \text { *bKra.shis da.lta [(kha.lag) ga.re yin.na'ang] bzas-tshar-song. } \\
& \text { Tashi now food what YIN.NA'ANG eat-finish-AUX } \\
& \text { Intended: } \approx \text { 'Tashi finished eating any food now.' } \\
& \text { bKra.shis da.lta (kha.lag) bzas-tshar-song. } \\
& \text { Tashi now food eat-finish-AUx } \\
& \text { 'Tashi just finished eating right now.' }
\end{aligned}
$$

Episodic descriptions simply claim the existence of a particular type of event: here, (37) asserts that there was a completion of an eating event, in the past, ${ }^{17}$

\footnotetext{
${ }^{16}$ Alternatively, if worlds where the uniqueness requirement is not met are filtered out of the base of modal quantification, as discussed above in footnote 13 above, the modal quantification becomes vacuous.

17 The auxiliary song expresses both past tense and direct evidentiality (Garrett 2001).
} 
in the halo of the speech time 'now.' There is no overt modal/temporal operator. Let us assume, following Kratzer 1986, that the conditional in wh-yin.na'ang in such a case will restrict the modal base of a high, covert epistemic necessity modal. ${ }^{18}$ Assuming that such a covert epistemic necessity modal quantifies over doxastically accessible worlds, we will again run into problems satisfying the uniqueness requirement of the specificational subject.

\subsection{Subtrigging}

As with FCIs in other languages, though, the restrictions on the distribution of wh-yin.na'ang may not be absolute bans. Specifically, the restriction due to issues with the granularity of modal quantification just introduced above only holds in so far as the subject of the specificational clause is definite; see (35). Instead, if the content of the conditional clause in wh-yin.na'ang takes an indefinite specificational subject, as schematized in (38), this problem could be avoided. ${ }^{19}$

\section{Alternative LF for (34) with indefinite specificational subject:

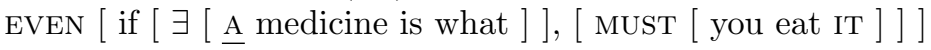

In particular, the structure of the form in (38) will not require the worlds (or situations) that are quantified over to have a unique individual that satisfies the property 'medicine,' which I claim led to the unavailability of the wh-yin.na'ang FCI in example (34). In reality, example (34) is judged as unacceptable, so this alternate parse in (38) with an indefinite specificational subject must not be available in example (34), if it is indeed ever available.

I propose that parses for wh-yin.na'ang with indefinite specificational subjects, as sketched in (38) above, are in principle available, and that this option holds the key to understanding another aspect of the distribution of FCIs. Specifically, I predict that the availability of the indefinite subject parse as in (38)which predicts the availability of the FCI without quantification over granular situations, and thus in a wider range of contexts - should only be as good as the general availability of specificational copular clauses with indefinite subjects.

It has been independently observed that subjects of specificational copular clauses are generally definite, but tolerate certain exceptions:

18 Alternatively, there simply is no universal modal/temporal operator in (36) for the conditional to restrict. Under this approach, there is no way for the scalar inference of wh-yin.na'ang's EVEN to be satisfied.

${ }^{19}$ Here I use a pronoun it in the consequent clause, in the position corresponding to the surface position of wh-yin.na'ang. It cannot be a (simple) definite description ("THE $P$ ") as in (35) above, as the relevant individual (concept) is not unique in the antecedent clause situation, which is also the situation of evaluation for the consequent clause. What is needed here instead is a donkey pronoun or similar, which will pick out the particular individual (concept) witness of the indefinite in the conditional antecedent. 


\section{Indefinite specificational subjects improve with modification:}

a. $*$ A doctor is John.

(Heycock and Kroch 1999: 379)

b. $\checkmark$ One person who might help you is Mary.

(Higgins 1973: 270)

In particular, modification - especially by relative clauses - seems to lead to acceptability. See e.g. See e.g. Mikkelsen 2005: ch. 8, Heycock 2012, Comorovski 2007, and more recently Milway 2020 for discussion.

I suggest that this restricted acceptability of indefinite specificational subjects and its amelioration as in (39) is in turn responsible for the similar amelioration of FCIs in some environments when modified, dubbed "subtrigging" by LeGrand (1975). Tibetan exhibits this subtrigging effect as well: Example (40) differs from the unacceptable (34) in the addition of a relative clause on the nominal domain and is judged as perfectly acceptable.

\section{Wh-yin.na'ang in (34) improves with modification:}

[[RC Sman.pa sprad-pa-'i] sman ga.re yin.na'ang] za-dgos-red. doctor give-REL-GEN medicine what YIN.NA'ANG eat-must-AUX

'[You] must take any medicine [RC that the doctor gives [you]].'

Again, taking the morphology of the FCI seriously - in this case, that whyin.na'ang involves a copular description-led to this novel connection between the behavior of FCIs and specificational copular clauses. I will leave a further understanding of the nature of this effect itself for future work.

Finally, we should also wonder whether the explanation for FCI subtrigging effects that I suggest here can or should be extended to account for apparently parallel subtrigging contrasts in languages such as English (41), where FCIs do not obviously reflect the involvement of a specificational copula. I will also leave the exploration of this question for future work.

\section{Parallel subtrigging with English any:}

a. ?? You must take any medicine.

b. $\checkmark$ You must take any medicine that the doctor gives you.

\section{Summary and Outlook}

This paper develops a new compositional semantics for universal free choice, from the predictable interactions of a number of ingredients. A specificational copular conditional clause describes an individual concept which the consequent then makes reference to. The conditional restricts the modal base of a modal/temporal operator in the sentence. And finally, the scalar particle EVEN associating with a $w h$-indefinite, enforces that the modified modal/temporal operator be a universal quantifier over situations. This leads indirectly to a kind of universal quantification over individuals in the domain of the FCI. The end result is a new approach to the universal force of universal FCIs, without directly prescribing or deriving this force. Furthermore, we have seen that this approach offers a 
new analytic possibility for reducing so-called "subtrigging" effects to an independently observed constraint on indefinite subjects in specificational copular clauses.

Most importantly, this proposal is not a hypothetical proof-of-concept. The expression of universal free choice in Tibetan, documented here, transparently involves these ingredients: a concessive conditional clause (even if) with a copular description, ranging over different possible individual referents in the domain of a $w h$-word.

If this analytic approach for universal free choice is truly successful, we might imagine that other languages would also express universal free choice claims in this way. There is recent work suggesting exactly this. For example, Rahul Balusu $(2019 ; 2020)$ has investigated different uses of concessive conditional expressions in a range of Dravidian languages; one such use is the formation of FCIs with exactly the same surface morphological makeup as in Tibetan: a wh-word with a copula and concessive conditional ending. Balusu also describes these copular descriptions as specificational.

\section{Morphologically parallel FCIs in Dravidian languages:}
a. Een-aad-ar-uu tinnutteene.
what-COP-COND-EVEN eat.will
'I'll eat anything.'
Kannada (Balusu 2020)
b. Ravi eed-ai-naa tinTaaDu.
Ravi what-COP-COND.EVEN eat.will
'Ravi will eat anything / something or other.'

Telugu (Balusu 2019: 46)

There are, however, some subtle differences in these constructions amongst different Dravidian languages, and between them and Tibetan. For example, Telugu wh-ai-naa FCIs allow both universal 'anything' as well as existential 'something or other' readings, although Kannada and Tibetan do not have such existential readings. See Balusu 2019, 2020 for discussion.

Additional evidence comes from the form of universal FCIs in Japanese, which appear to be formed of a wh-phrase with a particle demo, as in (43a). On the identity of this particle demo, Nakanishi (2006: 141) states, "-Demo can be morphologically decomposed into the copular verb - de followed by -mo [even]. However, it is not clear whether this decomposition is necessary." In recent work, however, Hiraiwa and Nakanishi (to appear) push the decompositional hypothesis a step further, specifically proposing that Japanese wh-demo FCIs have the underlying structure in $(43 \mathrm{~b})$, with a type of ellipsis obscuring the conditional morphology. ${ }^{20}$

\footnotetext{
$\overline{20}$ The copula in Japanese involves the copular marker de as well as the existential verb ar-, making de ar-te in (43) the expected verb form for a copular conditional. See e.g. Nishiyama 1999.
} 


\section{Morphologically similar FCI in Japanese:}

a. Nan-demo tabemasu. $\rightarrow$ b. nan(i) de ar-te mo what-DEMO eat.will 'I will eat anything.'

what COP EXIST-COND EVEN

(Hiraiwa and Nakanishi, to appear)

Whether expressions with demo indeed always reflect the structure in (43b) in the synchronic grammar of Japanese - or if the hypothesized structure in (43b) is better thought of as the diachronic source for what is now a single grammaticalized particle, demo - in my opinion warrants further debate. Still, the parallel as in (43) is additional fodder for the broad cross-linguistic viability of the decompositional approach to universal free choice developed here. See also Haspelmath 1997: 135-140 for discussion of indefinite expressions in many other languages which also exhibit morphological traces of copulas and concessive conditional morphology, some of which are still clearly FCIs, whereas others have extended to other indefinite types (pp. 149-150).

Furthermore, each of these concessive copular conditional expressions in both Dravidian languages and Japanese have a number of additional uses, which in fact largely overlap with the range of uses for Tibetan yin.na'ang (Erlewine 2020). The clear parallels in both the morphosyntactic composition and interpretational range of these expressions, across these genetically unrelated languages, further strengthens the motivation to take the decompositional approach to these expressions seriously, as well as to better document and understand the microvariation observed in their fine-grained behavior.

\section{References}

Arregi, K., Francez, I., Martinović, M.: Three arguments for an individual concept analysis of specificational sentences. Nat. Lang. Linguist. Theory, to appear

Arregui, A., Rivero, M.L., Salanova, A.: Cross-linguistic variation in imperfectivity. Nat. Lang. Linguist. Theory 32, 307-362 (2014)

Balusu, R.: The anatomy of the Dravidian unconditional. In: Cho, S.-Y. (ed.) Proceedings of GLOW in Asia XII, pp. 40-59. The Korean Generative Grammar Circle (2019)

Balusu, R.: Unconditional-FCIs of Dravidian. Presented at FASAL 10 (2020)

Beck, S.: Intervention effects follow from focus interpretation. Nat. Lang. Semant. 14, 1-56 (2006)

Branan, K., Erlewine, M.Y.: Anti-pied-piping. National University of Singapore (2020, manuscript)

Chierchia, G.: Logic in Grammar: Polarity, Free Choice, and Intervention. Oxford University Press (2013)

Cipria, A., Roberts, C.: Spanish imperfecto and pretérito: truth conditions and aktionsart effects in a situation semantics. Nat. Lang. Semant. 8, 297-347 (2000)

Comorovski, I.: Constituent questions and the copula of specification. In: Comorovski, I., von Heusinger, K. (eds.) Existence: Semantics and Syntax. SLAP, vol. 84, pp. 49-77. Springer, Dordrecht (2008). https://doi.org/10.1007/978-1-4020-6197-4_2

Elbourne, P.: Definite Descriptions. Oxford University Press (2013)

Erlewine, M.Y.: Wh-quantification in alternative semantics. Presented at GLOW in Asia XII, Dongguk University, Seoul (2019) 
Erlewine, M.Y.: Counterexpectation, concession, and free choice in Tibetan. In: Whitmal, A., Asatryan, M., Song, Y. (eds.) Proceedings of NELS 50, vol. 1, pp. 227-236 (2020)

Erlewine, M.Y.: Wh-quantification in Alternative Semantics. National University of Singapore, in prep, manuscript

Erlewine, M.Y., Kotek, H.: Even-NPIs in Dharamsala Tibetan. Linguist. Anal. 40, 129-165 (2016)

von Fintel, K.: Restrictions on quantifier domains. Doctoral dissertation, University of Massachusetts (1994)

Garrett, E.J.: Evidentiality and assertion in Tibetan. Doctoral dissertation, University of California at Los Angeles (2001)

Gawron, J.M.: Universal concessive conditionals and alternative NPs in English. In: Condoravdi, C., de Lavalette, G.R. (eds.) Logical Perspectives on Language and Information, pp. 73-106. CSLI Publications (2001)

Giannakidou, A.: The meaning of free choice. Linguist. Philos. 24, 659-735 (2001)

Goldstein, M.C. (ed.): The New Tibetan-English Dictionary of Modern Tibetan. University of California Press (2001)

Hamblin, C.: Questions in Montague English. Found. Lang. 10, 41-53 (1973)

Haspelmath, M.: Indefinite Pronouns. Oxford (1997)

Heim, I.: E-type pronouns and donkey anaphora. Linguist. Philos. 13, 137-177 (1990)

Heycock, C.: Specification, equation, and agreement in copular clauses. Can. J. Linguist. 57, 209-240 (2012)

Heycock, C., Kroch, A.: Pseudocleft connectedness: implications for the LF interface level. Linguist. Inquiry 30, 365-397 (1999)

Higgins, F.R.: The pseudo-cleft construction in English. Doctoral dissertation, Massachusetts Institute of Technology (1973)

Hiraiwa, K., Nakanishi, K.: Free choice and existential indeterminates as hidden clauses. In: Sinitsyna, J., Tatevosov, S. (eds.) Proceedings of WAFL 15, to appear

Hirsch, A.: A compositional semantics for wh-ever free relatives. In: Proceedings of Sinn und Bedeutung 20, pp. 341-358 (2016)

Jackendoff, R.: Semantic Interpretation in Generative Grammar. MIT Press (1972)

Karttunen, L., Peters, S.: Conventional implicature. In: Oh, C.-K., Dinneen, D.A. (eds.) Syntax and Semantics: Presupposition, vol. 11, pp. 1-56. Academic Press (1979)

Kay, P.: Even. Linguist. Philos. 13, 59-111 (1990)

Kluck, M.: Sentence amalgamation. Doctoral dissertation, University of Groningen (2011)

Kotek, H.: Composing questions. Doctoral dissertation, Massachusetts Institute of Technology (2014)

Kotek, H.: Composing Questions. MIT Press (2019)

Kratzer, A.: Conditional necessity and possibility. In: Bäuerle, R., Egli, U., von Stechow, A. (eds.) Semantics from Different Points of View, pp. 117-147. Springer, Heidelberg (1979). https://doi.org/10.1007/978-3-642-67458-7_9

Kratzer, A.: Conditionals. In: Papers from the Parasession on Pragmatics and Grammatical Theory, pp. 115-135. Chicago Linguistic Society (1986)

Kratzer, A.: An investigation into the lumps of thought. Linguist. Philos. 12, 607-653 (1989)

Kratzer, A., Shimoyama, J.: Indeterminate pronouns: the view from Japanese. In: Otsuka, Y. (ed.) The Proceedings of the Third Tokyo Conference on Psycholinguistics (TCP 2002), pp. 1-25. Hitsuji Syobo, Tokyo (2002) 
König, E.: Conditionals, concessive conditionals, and concessives: areas of contrast, overlap, and neutralization. In: Traugott, E.C., ter Meulen, A., Reilly, J.S., Ferguson, C.A. (eds.) On Conditionals, pp. 229-246. Cambridge University Press (1986)

Lahiri, U.: Focus and negative polarity in Hindi. Nat. Lang. Semant. 6, 57-123 (1998)

Lakoff, G.: Syntactic amalgams. In: Proceedings of CLS 10, pp. 321-344 (1974)

Lee, Y.-S., Horn, L.: Any as indefinite plus even. Yale University (1995, manuscript)

LeGrand, J.: Or and any: the syntax and semantics of two logical operators. Doctoral dissertation, University of Chicago (1975)

Lewis, D.: Adverbs of quantification. In: Keenan E.L. (ed.) Formal Semantics of Natural Language, pp. 3-15. Cambridge University Press (1975)

Menéndez-Benito, P.: The grammar of choice. Doctoral dissertation, University of Massachusetts Amherst (2005)

Menéndez-Benito, P.: On universal free choice items. Nat. Lang. Semant. 18, 33-64 (2010)

Mikkelsen, L.: Copular Clauses: Specification, Predication, and Equation. Benjamins (2005)

Milway, D.: The contrastive topic requirement on specificational subjects. Can. J. Linguist./Revue canadienne de linguistique 65, 181-215 (2020)

Nakanishi, K.: Even, only, and negative polarity in Japanese. In: Proceedings of SALT 16, pp. 138-155 (2006)

Nishiyama, K.: Adjectives and the copulas in Japanese. J. East Asian Linguist. 8, 183-222 (1999)

Ramchand, G.C.: Questions, Polarity and Alternative Semantics. Oxford University (1996, Manuscript)

Ramchand, G.C.: Questions, polarity and alternative semantics. In: Proceedings of NELS 27, pp. 383-396. GLSA (1997)

Rawlins, K.: (Un)conditionals: an investigation in the syntax and semantics of conditional structures. Doctoral dissertation, University of California Santa Cruz (2008a)

Rawlins, K.: Unifying if-conditionals and unconditionals. In: Friedman, T., Ito, S. (eds.) Proceedings of SALT 18, pp. 583-600 (2008b)

Rawlins, K.: (Un)conditionals. Nat. Lang. Semant. 21, 111-178 (2013)

Romero, M.: Concealed questions and specificational subjects. Linguist. Philos. 28, 687-737 (2005)

Rooth, M.: Association with focus. Doctoral dissertation, University of Massachusetts, Amherst (1985)

Rooth, M.: A theory of focus interpretation. Nat. Lang. Semant. 1, 75-116 (1992)

Shimoyama, J.: Internally headed relative clauses in Japanese and E-type anaphora. J. East Asian Linguist. 8, 147-182 (1999)

Szabolcsi, A.: Unconditionals and free choice unified. In: Proceedings of SALT 29, pp. 320-340 (2019)

Tournadre, N.: Arguments against the concept of 'conjunct'/'disjunct' in Tibetan. In: Chomolangma, Demawend und Kasbek, Festschrift für Roland Bielmeier, pp 281$308(2008)$

Tournadre, N., Dorje, S.: Manual of Standard Tibetan: Language and civilization. Snow Lion Publications (2003) 
Open Access This chapter is licensed under the terms of the Creative Commons Attribution 4.0 International License (http://creativecommons.org/licenses/by/4.0/), which permits use, sharing, adaptation, distribution and reproduction in any medium or format, as long as you give appropriate credit to the original author(s) and the source, provide a link to the Creative Commons license and indicate if changes were made.

The images or other third party material in this chapter are included in the chapter's Creative Commons license, unless indicated otherwise in a credit line to the material. If material is not included in the chapter's Creative Commons license and your intended use is not permitted by statutory regulation or exceeds the permitted use, you will need to obtain permission directly from the copyright holder. 